\title{
Alleviation the scouring problem downstream of dam spillways through a reversed cross-jet flow dissipator
}

\author{
Amad.Deen A. Alghwail \\ Elmergib University, Faculty of Engineering, Al Khums, Libya and PhD student at Union-Nikola Tesla \\ University, Belgrade, Serbia
}

\begin{abstract}
In this paper, a reversed cross-jet flow is developed to dissipate the energy of flow over an ogee weir spillway. The problem is handled analytically and experimentally. Both measured and calculated data indicate a great effect on the forced hydraulic jump characteristics compared to those describing the characteristics of the free jump condition. The obtained results revealed that, the reversed flow, can speed up the transition from supercritical to subcritical flow by creating a forced perfect jump starting at the contracted section and consequently, shortening the protection length needed to counter the problem of scouring downstream of the channel, since the length of the perfect hydraulic jump was reduced by $19 \%$, while reduction in the length of the stilling basin amounted to $79 \%$, in comparison to the case without a dissipator. The efficiency of such energy dissipation methods can have a significant impact on the overall cost of hydraulic structures projects.
\end{abstract}

\section{INTRODUCTION}

Dam spillways are commonly built in rivers and streams having alluvial bed materials (erodible materials) such as sand, clay and silt. A spillway allows a vast amount of water to be released from the reservoir over a short space of time resulting in flow of very high discharge and velocity. This normally takes the form of highly turbulent supercritical flow, in the spillway and its immediate downstream of the channel. The high flow velocity leads to a bed shear stress greatly higher than in the absence of the structure, causing significantly increased sediment transport downstream of the structure. The channel bed level becomes eroded as a result and this is commonly known as local scour, as illustrated in Figure 1. Successive or continuous scouring can undermine the foundation of the spillway and then leading to the failure of the structure itself in the worst scenario, (Hager 2007, Simon \& Korom 1997). As such, local scouring must be prevented.

To alleviate the scouring problem, it is necessary to protect the channel by lining downstream of the structure until the flow becomes subcritical, where the flow velocity is substantially lower. Under natural conditions, river flow is normally in a subcritical state and where a supercritical flow occurs it will reverse back to subcritical at some point further downstream. The reversal from supercritical to subcritical flow always involves a hydraulic jump as demonstrated in Figure 1.
For structural safety, it is a necessity to provide channel protection to counter the problem of scouring. To minimise the cost of such provision, measures are needed to speed up the transition from supercritical to subcritical flow. The efficiency of such measures will have a direct impact on economics of hydroelectric schemes involving spillway structures.

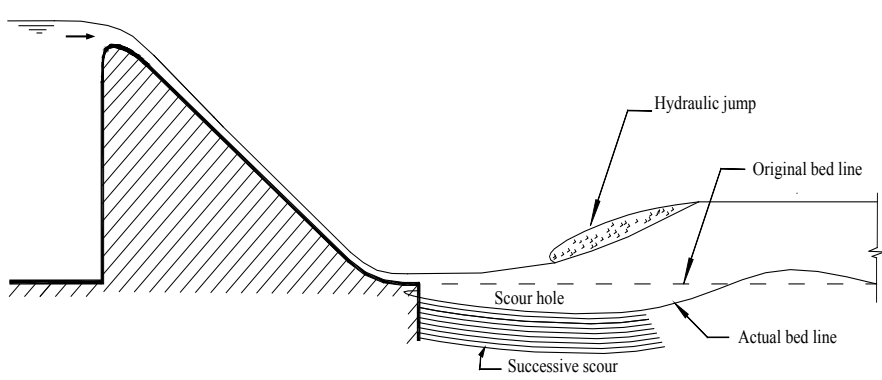

Figure 1. Scour process downstream a spillway.

The cost of channel protection is directly proportional to the distance between the spillway and where the hydraulic jump takes place. Two approaches can be taken to move the hydraulic jump forward, thus reducing the distance. Raising the downstream flow depth is relatively easily achieved as in the case of a stilling basin.

Stilling basins are a cost effective means to reduce the problem of scouring but they are normally used along with other means of energy dissipation to enhance their performance. Baffle blocks, end sill, 
positive and negative steps, splitter block and buckets may be used as barriers or obstructions in the stilling basin to reduce the flow velocity and shorten the hydraulic jump length, resulting in a better energy dissipation without increasing the water depth in the channel (Novak et al., 2001; Manoochehr et al., 2011; Verma, 2000). As a results there have been great efforts amongst engineers and researchers towards developing efficient but also cost effective solutions.

A good example is the stepped spillway. As water flows down the steps, turbulent mixing and diffusion can produce more energy dissipation compared to that on smooth spillways as shown by (Barani et al., 2005; Chafi et al., 2010). A numerical model by Abbasi \& Kamanbedast (2012) showed that, increasing the steps' lengths and heights lead to an increase in water energy dissipation, which means more costs of construction for energy dissipation. Vischer \& Hager (1995) recommend using Ski jump buckets, when the flow velocity is high, more than about $15-$ $20 \mathrm{~m} / \mathrm{s}$. On the other hand, problems of cavitation, abrasion, and uplift with stilling basins may exist. A Ski jump's deflector is a simple design element to deflect the flow, without problems regarding cavitation damage. A significant disadvantage of the bucket is the increased level of choking inception, and this effect has to be carefully checked. Damage mainly due to erosion downstream of the bucket and choking of an upstream bottom outlet channel may result otherwise.

At outlets and spillways of the stilling basins, cavitation may occur on the lateral and rear faces of baffle blocks, sills and protuberances (Novak \& Cabelka, 1981; Vischer \& Hager, 1998). Stilling basin with baffle blocks is not recommended when the flow velocity is more than $20-30 \mathrm{~m} / \mathrm{s}$ due to the risk of erosion and cavitation damage to the structure Chanson (2004). (Boes \& Hager, 2003; Amador et al., 2009) recommended a critical velocity for cavitation inception in the flow, prior to air entrainment of approximately 20 and $15 \mathrm{~m} / \mathrm{s}$, respectively. However, the use of specific discharge and velocity as a design recommendation of spillways to prevent cavitation occurrence may be misguided without knowing the actual conditions of when and if cavitation will form.

\subsection{Energy dissipation by using counter-flow}

At a fundamental level, energy dissipation of a fluid flow relies on the internal friction due to viscous effects and turbulent diffusion. The frictional head loss is directly proportional to the velocity gradient while diffusion depends on the intensity of the turbulence. Air entrainment enhances the turbulent intensity while a high velocity jet impacting on the stationary or low velocity liquid increases both the level of turbulence and velocity gradient as in the case of stepped spillways. Installing baffles in a stilling basin forces the flow to change direction abruptly, which generates highly non-uniform flow and thus increased velocity gradient and head loss (commonly known as local head losses). As water flow hits obstructions, turbulence also results. It is, therefore, a key to the energy dissipation process that any method in use must maximise enhancement of turbulence and velocity gradient. This is best demonstrated by the counter flow approach.

The concept of energy dissipation by counter flow depends on collision process between the opposing flows. The collision of two opposing flows may happen in air or within a stilling basin. Komora (1969) suggested a technique that produces a collision of jets in the air. The three spreader blocks are located at the end of the channel and deflect a part of the flow into the air. Another part of the flow passing between the blocks is thrown off by a trajectory bucket. The water jets are mixed intensively with air and a calm flow regime is secured behind the stilling basin. It was shown that the length of the floor is decreased by $10 \mathrm{~m}$, resulting in a significant reduction in the volume of the earth and concrete work for the spillway. A counter current stilling basin energy dissipator was designed by Vollmer \& Khader (1971), with a splitter block having a V- shaped structure installed on the stilling basin floor to divide the incoming flow into two parts. The major part of the divided flow is directed into the flow direction and is joined by a circular arc structure so as to meet in the opposite direction which creates a heavy loss of water energy due to collision. The remaining portion of the divided flow is directed in the opposite direction forming small vortices at the upstream corners of the basin which properly utilises the complete basin area in front of the circular arc like structure for energy dissipation. Kao (1971), carried out experimental and theoretical analysis to study the effect of floor jet on the formation of the hydraulic jump. He used a horizontal rectangular channel with an open slot across the channel at the middle portion of its bottom to provide a jet flow inclined towards the upstream, as shown in Figure 2. The results indicated that the control of a hydraulic jump by a submerged cross-jet, instead of solid chute blocks and baffle piers is possible and the tailwater depth is reduced and much energy was dissipated by reverse jet compared with a free hydraulic jump. Also, the jet discharge and the jet geometry may increase flow turbulence which causes much dissipation of energy.

\section{METHODOLOGY}

As stated above, there is always a need for new and/or improved methods of energy dissipation. The current study explores the counter-flow concept as an energy dissipation method by systematic exami- 
nation of the flow. The basic principle of counterflow is splitting the flow into two flows and then directing them against each other. Under simple flow conditions, the energy dissipation is examined from both theoretical and experimental perspectives. The fundamental energy, momentum and continuity equations were applied to achieve some predictions of parameters such as, the conjugate depth ratio, the discharge through the slot and the relative energy loss, the condition of a perfect hydraulic jump and associated loss of energy. For a given flow rate, the normal flow depth in the channel depends on the channel bed slope and bed surface condition. It should be possible to estimate where the hydraulic jump takes place and the distance from the toe of structure. As the stilling basin is normally an integral part of the overall structure, this distance is referred to as the floor length. The greater the floor length, the more construction material is needed, therefore, the greater cost.

The actual process of energy dissipation involving complex structures and impacts of flow is very complicated and it requires physical modelling under controlled laboratory conditions in order to gain an insight of the flow behaviour. A number of physical models of different designs were constructed to create different counter flow configurations. The effect of the counter-flow; width, location and angle of slot is experimentally studied to obtain the proper design values of counter-flow dimensions. Under an identical set of flow conditions, all models were tested with a series of key flow parameters measured. Through these measurements, the flow characteristics and the energy dissipation efficiency is directly evaluated. It will also be possible to quantify different stages of the energy dissipation as water travels from upstream to downstream of the spillway. Unlike previous related studies where the focus was on resulting energy dissipation, the current study has developed a fundamental understanding of the process through measurements of a range of key parameters involved in the process. Therefore, the effectiveness of the energy dissipation methods is assessed from an energy perspective as well as that of economics.

\section{ANALYTICAL STUDY}

The main purpose in the analytical study, is to predict theoretical equations including the parameters involved in the problem. These equations might be used for estimating, the conjugate depths, the Energy loss, as well as the characteristics of a forced hydraulic jump, in the case of a cross-jet existence, (Counter Flow).

To get both the conjugate depths and the Energy loss equations in this case, the contracted depth at the toe of the ogee weir spillway, in addition to the discharge of the cross-jet, (slot) should be found, primarily. The essential equations of flow; Energy, momentum and continuity equation were used to develop the theoretical solutions. The back face of an ogee weir spillway, is acting as an inclined surface. Therefore, the reversed cross-jet dissipator is applied to dissipate flow energy downstream of the spillway.

\subsection{Determination of the contracted depth downstream of an ogee weir spillway}

The contract depth has great effects on flow conditions downstream of the spillway, such as, Froude number, flow velocity, the characteristics of the formed hydraulic jump and the required measures for any energy dissipation design. Therefore, many procedures are used, to determine the value of the contracted depth accurately.

Apply the energy equation from the approach section (1-1) to the contracted section (2-2) at which the contraction of flow occurs. For precise estimation of the contracted depth, the energy loss $\left(h_{L 1-2}\right)$ between the two mentioned sections should be considered. As shown in the Figure 2, the specific energy equation can be found:

$H_{0}=y_{c}+\frac{\alpha_{2} v_{c}^{2}}{2 g}+h_{L 1-2}$

where $y_{c}$ and $v_{c}=$ the flow depth and velocity at contracted section, respectively. The energy loss on the spillway surface can be expressed as: $h_{L l-2}=\zeta \cdot v_{c}{ }^{2} /$ $2 g$, where; $\zeta=$ the head loss coefficient. Considering $\alpha \mathrm{Z}=\alpha_{2}=1.0$, Equation 1, becomes:

$H_{0}=y_{c}+\frac{v_{c}^{2}}{2 g}(1+\xi)$

from which the actual velocity $v_{c}=v_{a c t}$ is given as:

$$
v_{a c t}=\frac{1}{\sqrt{1+\xi}} \sqrt{2 g H_{0}}
$$

neglecting $h_{L l-2}$, the theoretical velocity $v_{c}=v_{t h}$ is written as: $v_{t h}=\left(2 g\left(H_{0}\right)\right)^{0.5}$, since the velocity coefficient $C_{v}$ is the ratio between the actual and theoretical velocities, $C_{v}=v_{a c t} / v_{t h}$, then $C_{v}=1 /(1+\zeta)^{0.5}$, substituting for $C_{v}, v_{2}=q / y_{c}$ and $q^{2}=y_{c r}{ }^{3} / g$ in Equation 2, yields;

$y_{c}{ }^{3}-H_{0} y^{2}+\frac{y_{c_{r}}{ }^{3}}{2 C_{v}{ }^{2}}=0$

Equation 3, is a cubic equation for $y_{c}$. Using Cardano's method to derive the contracted depth $y_{c}$. Considering the free flow condition, the flow depth at the spillway toe $y_{c}$ can be calculated as: 
$y_{c}=\frac{H_{0}}{3}\left[1-2 \cos \left(\frac{\gamma}{3}+\frac{\pi}{3}\right)\right]$

where;

$\cos \gamma=\left(1-\frac{4 \times 27 y_{c_{r}}{ }^{3}}{2 C_{v}{ }^{2} \cdot 8 H_{0}{ }^{3}}\right)$

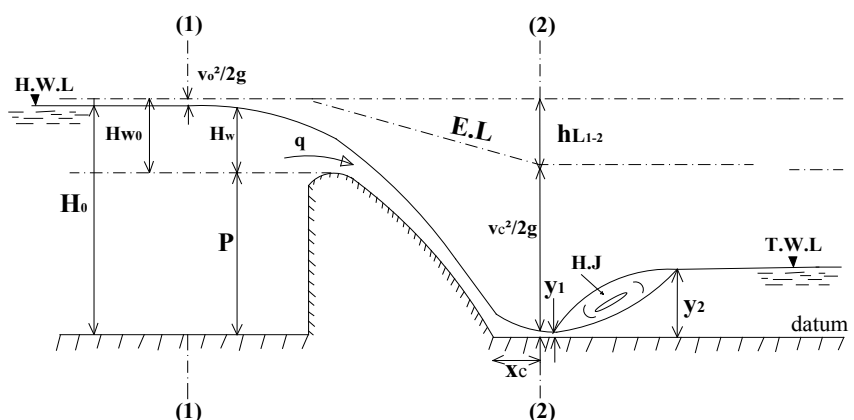

Figure 2. Determination of the contracted depth

By using the experimental data, an empirical formula presented by Abourohim (1991), can be used to estimate the velocity coefficient $C_{v}$ in the form; $C_{v}=$ $1+0.07 \ln \left(H_{w} / p\right)$ for values of $0.05<H_{w} / p \leq 1$.

\subsection{Determination of the cross-jet discharge}

Referring to Figure 3, applying the energy equation at section (0-0) and (S-S), one obtains;

$$
H=\frac{P_{s}}{\gamma_{W}}+\frac{\alpha_{s} v_{s}^{2}}{2 g}+h_{L_{0-S}}
$$

substituting $\left(p_{s} / \gamma_{w}\right)=y_{s}$; and $\alpha_{1}=1$, (Eq. 5) becomes;

$$
H=y_{s}+\frac{v_{s}^{2}}{2 g}+h_{L_{0-S}}
$$

substituting for $h_{s}=H-y_{s}$ in Equation 6, can be rewritten in the form;

$v_{s}=C_{v} \sqrt{2 g h_{s}}=C_{v_{S}} \sqrt{2 g\left(H-y_{s}\right)}$

where $C_{v \mathrm{~s}}=$ the coefficient of velocity for the discharging jet issuing from the slot.

With regard to Figure 3, tan $\alpha=\left(y_{2}-y_{1}\right) / L_{J}$ and $\tan \alpha=\left(y_{s}-y_{1}\right) / x$, from which $y_{s}=y_{1}+x \tan \alpha$, then Equation 7, can be rearranged as follows;

$v_{s}=C_{v_{S}}\left[2 g\left(H-y_{1}-x \tan \alpha\right)\right]^{0.5}$

Since the slot is considered as a submerged oriface, then the coefficient of contraction of the oriface $C_{c}$ is assumed to be unity .Consequently, both velocity and discharge coefficients of slot $C_{v s}$ and $C_{d s}$ are being same. Thus;

$v_{s}=C_{d_{S}} \sqrt{2 g y_{2}}\left[\frac{H}{y_{2}}-\frac{y_{1}}{y_{2}}-\frac{x}{L_{j}}\left(1-\frac{y_{1}}{y_{2}}\right)\right]^{0.5}$

where $x=$ the horizontal distance between the centre of the slot and the contracted section; and $C_{d s}=$ the slot coefficient of discharge. Considering that the width of the flow at section (S-S) is the same as the slot width, the continuity equation gives, $Q_{S}=b B v_{s}$, where $B=$ the width of the channel; and $b=$ the width of slot. Substituting for $v_{s}$ from Equation 9, the slot discharge is given as;

$Q_{S}=\beta_{1} B b \sqrt{2 g y_{2}}$

where;

$\beta_{1}=C_{d_{S}}\left[\frac{H}{y_{2}}-\frac{y_{1}}{y_{2}}-\frac{x}{L_{j}}\left(1-\frac{y_{1}}{y_{2}}\right)\right]^{0.5}$

(0)

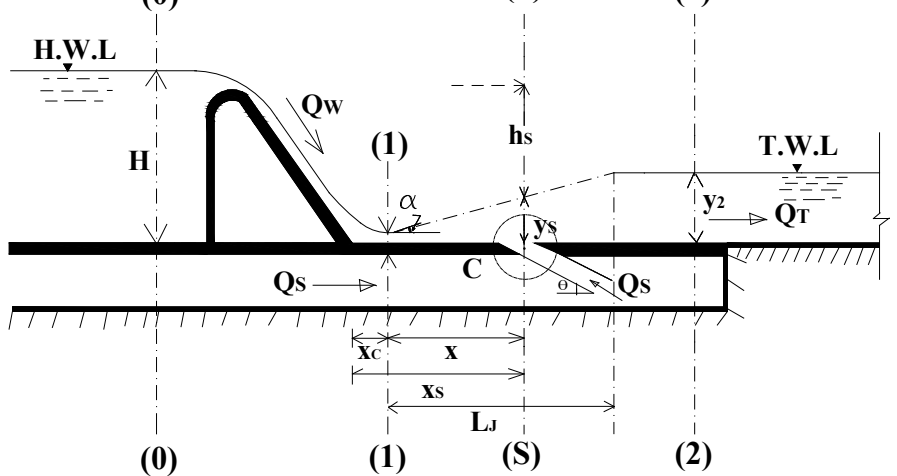

Figure 3. Determination of cross-jet discharge.

\subsection{Determination of the conjugate depth ratio}

In the present study, the slot providing the reverse cross-jet is fed from the headwater side upstream of the weir. Therefore, the two streams, the main and cross-jet flows, are acting under the same upstream head. The momentum equation can be applied for the control volume, bounded by section (1) and (2), Figure 4, which includes the hydraulic jump as:

$\beta_{2} \rho Q_{2} v_{2}-\left(\beta_{1} \rho Q_{1} v_{1}-\beta_{s} \rho Q_{s} v_{s} \cos \theta\right)=\sum F_{x}=P_{1}-P_{2}$

where; $p_{1}$ and $p_{2}=$ the hydrostatic pressure acting at section (1) and (2), respectively; $y_{1}$ and $v_{1}=$ the water depth and the mean velocity at section (1).

Ignoring the friction losses along the jump length and considering that the Boussinesq factors at sections (1) and (2) equal unity, Equation 11, can be rewritten in the form; 
(2)

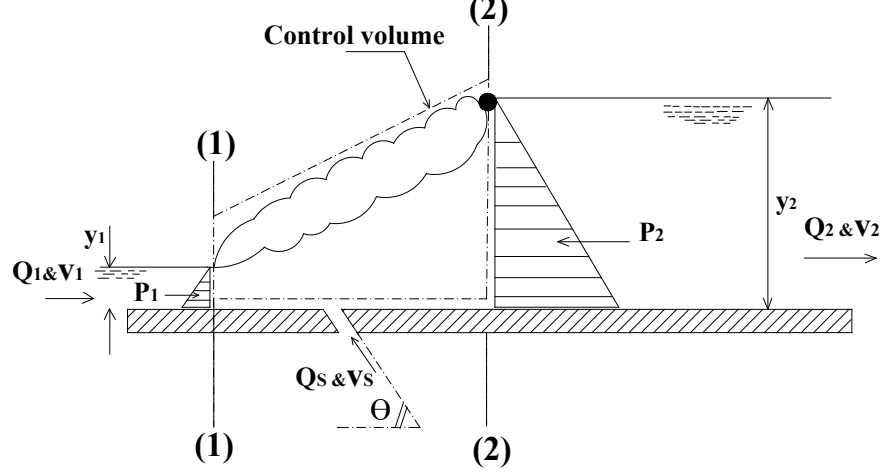

Figure 4. Control volume including hydraulic jump.

$\left(y_{1} / y_{2}\right)^{2}=1+2 q_{2} v_{2} / g y_{2}^{2}-2 q_{1} v_{1} / g y_{2}^{2}+\left(2 q_{s} v_{s} / g y_{2}^{2}\right) \cos \theta$

According to the principle of conservation of mass, and for a constant density: $q_{1}=q_{2}-q_{s}$. Substituting into (Eq. 12), where $v_{1}=q_{1} / y_{1}=\left(q_{2}-q_{s}\right) / y_{1}$ and solving for $\left(y_{1} / y_{2}\right)$ yields;

$\left(\frac{y_{1}}{y_{2}}\right)^{2}=1+\frac{2 v_{2}^{2}}{g y_{2}}-\frac{2 v_{2}^{2}}{g y_{1}}+\frac{4 v_{2} q_{s}}{g y_{1} y_{2}}-\frac{2 q_{s}^{2}}{g y_{1} y_{2}{ }^{2}}+\frac{2 q_{s} v_{s}}{g y_{2}{ }^{2}} \cos \theta$

putting $\phi=y_{1} / y_{2}$ and $F_{2}=v_{2} /\left(g y_{2}\right)^{0.5}$, substituting for $q_{s}$ for (Eq. 10), considering $\delta_{1}=b / y_{2}$ and solving for $\phi$, yields;

$\phi^{3}-\left(1+2{F_{2}}^{2}+4 \beta_{1}{ }^{2} \delta_{1} \cos \theta\right) \phi+2\left(F_{2}{ }^{2}-2 \sqrt{2} \beta_{1} \delta_{1} F_{2}+2 \beta_{1}{ }^{2}{\delta_{1}}^{2}\right)=0$

Equation 14, can be used to calculate the values of $\phi$ for knowing values of $y_{2}, q_{2}, H, x, b$ and $L_{J}$.

putting $b=0$ and in turn $\delta_{1}=0$ into Equation 14, the discharge of cross-jet vanishes and it is reduced to the well-known Belenger's formula, which relates the two conjugate depths of the free jump in the form, $\phi=y_{1} / y_{2}=0.5\left(\left(1+8 F_{2}^{2}\right)^{0.5}-1\right)$.

Using a similar analysis, we can get the relation between conjugate depths $y_{2} / y_{1}$ as a function of Froude number at the upstream of jump $F_{1}$ instead of Froude number at the downstream $F_{2}$, the following equation may be found:

$\psi=y_{2} / y_{1}=2 \sqrt{-a / 3} \cos [(N+2 \pi k) / 3]$

in which;

$a=-\left(1+2 F_{1}^{2}-4 \beta_{2}^{2} \delta_{2}^{2} \cos \theta\right)$;

$b=2\left(F_{1}^{2}+2 \sqrt{2} F_{1} \beta_{2} \delta_{2}+2 \beta_{2}^{2} \delta_{2}^{2}\right)$

$N=\cos ^{-1}\left[-b / 2 \sqrt{(-a / 3)^{3}}\right] ;$ and $k=0,1,2$.

\subsection{Energy dissipated by the forced jump}

The energy dissipation can be found by evaluation the difference between the total energy before the jump and the total energy after it. This can be written as follow:

$E_{L}=\left(y_{1}+v_{1}^{2} / 2 g\right)-\left(y_{2}+v_{2}^{2} / 2 g\right)$

substituting $\psi=y_{2} / y_{1}$ and $F_{1}=v_{1} /\left(g y_{1}\right)^{0.5}$ in (Eq. 16), we get;

$E_{L} / y_{1}=\left(1+F_{1}^{2} / 2\right)-\left(\psi+v_{2}^{2} / 2 g y_{1}\right)$

According to the principle of conservation of mass and for a constant density, $q_{2}=q_{1}+q_{s}$, substitution into Equation 17, we get;

$E_{L} / y_{1}=\left(1+F_{1}^{2} / 2\right)-\left(\psi+\left(q_{1}+q_{s}\right)^{2} / 2 g y_{1} y_{2}^{2}\right)$

putting $q_{1}=v_{1} y_{1} ; \delta_{2}=b / y$; and $q_{s}=\beta_{2} b\left(2 g y_{1}\right)^{0.5}$ from (Eq. 10) into (Eq. 18) and simplifying, one get;

$E_{L} / y_{1}=\left(1+F_{1}^{2} / 2\right)-\psi-1 / \psi^{2}\left[F_{1}^{2} / 2+\sqrt{2} F_{1} \beta_{2} \delta_{2}+\beta_{2}{ }^{2} \delta_{2}{ }^{2}\right]$

putting $\delta_{2}=0$, Equation 19, may be reduced to the classical equation which is used to calculate the energy losses for a simple free hydraulic jump.

\section{EXPERIMENTAL ARRANGEMENT AND EXPERIMENTS}

The present problem is theoretically handled, some coefficients are to be determined using the experimental data. In addition, the effect of the cross-jet (counter flow) must be experimentally studied to obtain the proper design values of slot dimensions; width, angle and location.

\subsection{Experimental set-up}

The experiments were conducted at the laboratory of fluid mechanics, Faculty of Engineering, Elmergib University, Al khums, Libya. The testing flume is $5.0 \mathrm{~m}$ long with a rectangular cross-section $25 \mathrm{~cm}$ high by $7.6 \mathrm{~cm}$ wide with $10 \mathrm{~mm}$ sides of transparent Perspex sheets. A submersible pump provides the source of water which is continuously flowing through the channel section providing a closed circuit water supply. A radial gate is installed in the working channel to control the water depth downstream of the spillway.

\subsection{The Dissipator Model}

The inclined surface of the spillway, is represented by an inclined plate joining the crest of the ogee weir to the testing flume bottom. It is $10 \mathrm{~mm}$ thick, $1.0 \mathrm{~V}$ : $0.7 \mathrm{H}$ slope, and $43.5 \mathrm{~cm}$ height $p$ as shown in Figure 5. The above slope of the back face of the spill- 
way was chosen according to the previous studies conducted by (Stephenson, 1991; Christodoulou, 1993; Chanson, 1994; Chamani \& Rajaratnam, 1999; USBR). Such a given slope prevents separation of flow from the inclined surface.

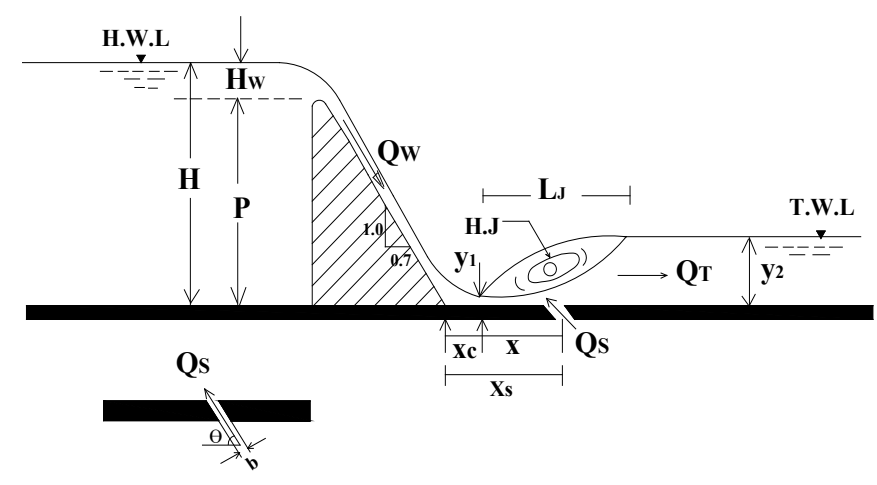

Figure 5. Details of dissipater model.

The headwater depth $H$ and tailwater depth $y_{2}$ were measured using a piezometric tube, fixed on a vertical scale of $0.50 \mathrm{~mm}$ accuracy and connected to the bottom of the testing flume. The contracted depth $y_{c}$ or the initial water depth $y_{1}$ was measured using a precision point gauge with reading accuracy of $0.10 \mathrm{~mm}$. The circulated flow was measured with a calibrated sharp edged rectangular weir, the obtained discharge equation may be expressed as;

$Q=0.27485 \times h^{1.578}$

where $Q=$ discharge $(1 / \mathrm{s})$; and $h=$ head over weir.

Seventeen experiments were carried out in the laboratory. For each experiment, five runs corresponding to five values of Froude number $F_{1}$ were carried out, then the total number of experiments equals $5 \times$ $17=85$ runs.

In the case of a perfect free jump, constant values of the discharge passing over the weir spillway, were $Q_{W}=0.5,1.0,1.50,2.0$ and $2.50(1 / \mathrm{s})$, corresponding to a headwater depth $H=45.70,46.98,48.05$, 48.98 and $49.85 \mathrm{~cm}$, respectively. For every discharge the contracted section is assigned and the contracted depth $y_{c}$ and its distance from the weir toe $x_{c}$ were measured. Using the tail gate, the position of the hydraulic jump is adjusted so that the front of the jump is immediately at the contracted section to obtain a perfect jump, where $y_{1}=y_{c}$. The tailwater depth and length of the jump $L_{J}$, were measured.

In the case of a perfect forced jump, the slot is installed. Considering constant values of both slot width $b=0.15 \mathrm{~cm}$ and inclination angle $\theta=15^{\circ}$, the slot location was fixed at distances $x_{s}=5,10,15,20$, 25 and $30 \mathrm{~cm}$. Considering $x_{s}=5.0 \mathrm{~cm}$, the pump is turned on and the control valve is adjust to give the same headwater depth $H$ used in the case of the free jump. In this case, the discharge passing over the weir spillway $Q_{W}$ remains constant as considered in the case of the free jump. Using the tail gate, the tailwater depth was gradually reduced until the jump front is located immediately at the contracted section. Here, the initial depth, $y_{1}$ or $y_{c}$ are still at the same value found in the case of the free jump since $Q_{W}$ is not changed. The tailwater depth $y_{2}$ and the length of forced jump $L_{J}$ are then measured. The head on the rectangular weir is measured and the total discharge $Q_{T}$ is then estimated using (Eq. 20), the discharge issuing from the slot is then found $Q_{S}=$ $Q_{T}-Q_{W}$.

The above steps are repeated for other values of $H$, considering other values of slot dimensions and locations, (fixing one value of slot dimension and changing the others), as illustrated in the table 1.

Table 1 . The tested values of the considered parameters.

\begin{tabular}{|c|c|c|}
\hline$\theta=15^{0}, b=0.15$ & $b=0.15, x_{s}=15$ & $\theta=45^{0}, x_{s}=15$ \\
\hline $\mathrm{cm}$ & $\mathrm{cm}$ & $\mathrm{cm}$ \\
\hline$x_{s}=5 \mathrm{~cm}$ & $\theta=15^{0}$ & $b=0.15 \mathrm{~cm}$ \\
\hline 10 & $30^{\circ}$ & 0.20 \\
\hline 15 & $45^{0}$ & 0.25 \\
\hline 20 & $60^{\circ}$ & 0.30 \\
\hline 25 & $75^{0}$ & \\
\hline 30 & $90^{\circ}$ & \\
\hline
\end{tabular}

Froude number $F_{1}$ ranges from 8.74 to 13.45 . In this range, the jump is well established, the roller and jump action is fully developed to cause appreciable energy loss. However, the water surface downstream of the jump is rough and wavy. The discharge passing over the weir ranges from 500 to $2500 \mathrm{~cm}^{3} / \mathrm{s}$, while the discharge passing through slot ranges from 72.50 to $412.40 \mathrm{~cm}^{3} / \mathrm{s}$. The total discharge ranges from 500 to $2912.40 \mathrm{~cm}^{3} / \mathrm{s}$. The relative slot discharge $\left(Q_{S} / Q_{T}\right)$ ranges from 0.039 to 0.439 .

The discharge passing over the weir ranges from 500 to $2500 \mathrm{~cm}^{3} / \mathrm{s}$, while the discharge passing through slot ranges from 72.50 to $412.40 \mathrm{~cm}^{3} / \mathrm{s}$. The total discharge ranges from 500 to $2912.40 \mathrm{~cm}^{3} / \mathrm{s}$. The relative slot discharge $\left(Q_{S} / Q_{T}\right)$ ranges from 0.039 to 0.439 .

\section{ANALYSIS AND DISCUSSION OF RESULTS}

Generally, the formed hydraulic jump can be described by: The conjugate depth ratio $\left(y_{2} / y_{1}\right)$, the relative length of jump $\left(L_{J} / y_{l}\right)$ and the relative energy dissipated through the jump $\left(E_{L} / y_{l}\right)$.

Excluding the parameters, which were kept constant, and using dimensional analysis, the following dimensionless relation for the conjugate depth $\left(y_{2} /\right.$ $y_{1}$ ) can be written, as;

$y_{2} / y_{1}=f\left(x_{s} / y_{1}, \theta, b / y_{1}, F_{1}, R_{N}\right)$ 
The influence of the viscous effect may be neglected due to the high values of Reynolds number involved in the study (Rajaratnam, 1976; Hager \& Bremen, 1989). Thus, the above relation can be expressed as;

$$
y_{2} / y_{1}=f_{1}\left(x_{s} / y_{1}, \theta, b / y_{1}, F_{1}\right)
$$

Similarly, for the relative length of jump and for the relative energy dissipation:

$$
\begin{aligned}
& L_{J} / y_{1}=f_{2}\left(x_{s} / y_{1}, \theta, b / y_{1}, F_{1}\right) \\
& E_{L} / y_{1}=f_{3}\left(x_{s} / y_{1}, \theta, b / y_{1}, F_{1}\right)
\end{aligned}
$$

Tables 2 and 3 summarize the measured and calculated data, respectively, describing the characteristics of the free jump condition. The measured values of the initial depth $y_{1}\left(y_{1}=y_{c}\right)$ are checked using (Eq.4), a maximum deviation of about $6 \%$ exists between the measured and calculated values of the

\begin{tabular}{|c|c|c|c|c|c|c|c|}
\hline$H$ & $Q_{W}$ & $x_{c}$ & $L_{J}$ & $y_{1}$ & $y_{2}$ & $F_{1}$ & $F_{2}$ \\
\hline $\mathrm{cm}$ & $\overline{\mathrm{cm}^{3} / \mathrm{s}}$ & $\mathrm{cm}$ & $\mathrm{cm}$ & $\mathrm{cm}$ & $\mathrm{cm}$ & & \\
\hline 45.7 & 500 & 3.00 & 23.0 & 0.29 & 5.0 & 13.45 & 0.19 \\
\hline 46.98 & 1000 & 5.32 & 35.0 & 0.5 & 7.5 & 11.88 & 0.2 \\
\hline 48.05 & 1500 & 8.25 & 45.0 & 0.73 & 9.6 & 10.1 & 0.21 \\
\hline 48.98 & 2000 & 11.00 & 53.0 & 0.94 & 11.25 & 9.22 & 0.22 \\
\hline 49.85 & 2500 & 13.50 & 61.0 & 1.13 & 12.75 & 8.74 & 0.23 \\
\hline
\end{tabular}
contracted depth

Table 2. Measured data for the perfect free jump.

\begin{tabular}{|c|c|c|c|c|c|}
\hline$\left(y_{2} / y_{1}\right)_{\mathrm{o}}$ & $\left(L_{J} / y_{1}\right)_{\mathrm{o}}$ & $\frac{E_{L}}{\mathrm{~cm}}$ & $\left(E_{L} / y_{l}\right)_{\mathrm{o}}$ & $C_{v}$ & $\frac{y_{1}}{\mathrm{~cm}}$ \\
\hline 17.24 & 79.31 & 21.43 & 73.91 & 0.79 & 0.28 \\
\hline 15.0 & 70.0 & 28.14 & 56.28 & 0.82 & 0.53 \\
\hline 13.15 & 61.64 & 28.17 & 38.59 & 0.84 & 0.77 \\
\hline 11.97 & 56.38 & 29.36 & 31.23 & 0.86 & 1.0 \\
\hline 11.28 & 53.98 & 31.23 & 27.64 & 0.87 & 1.2 \\
\hline
\end{tabular}

Table 3. Calculated data for the perfect free jump.

* Calculated values of the contracted depth using (Eq. 4)

The case of the free jump, in which the cross-jet does not exist, is investigated to provide a reference data set used to indicate the effect of the above parameters on the hydraulic jump characteristics and to compare the results obtained from the case of forced jump formed due to the cross-jet flow.

\subsection{Effect of the considered parameters on the characteristics of the forced hydraulic jump}

The issuing flow from the transverse slot hits the incoming flow falling over the weir. The colliding of two flows with each other will reduce the flow velocity and in turn increase the tailwater depth which pushes the formed jump to move towards the upstream side. The jump in this case is called a forced jump. Consequently, the cross-jet affects the charac- teristics of the forced jump such as; the length of the jump $L_{J}$, the conjugate depth ratio $y_{2} / y_{1}$ and the energy dissipated along the jump $E_{L}$.

The effect exerted on the forced jump characteristics mainly depends on the direction, location, velocity and the discharge of the cross-flow jet, as well as on Froude number $F_{1}$. Therefore, different locations $x_{s}$, angles $\theta$ and widths $b$ of the slot were tested considering the same values of both headwater depth $H$ and corresponding discharge $Q_{W}$ used before in the case of free jump.

The effect of the counter flow (existence of the transverse cross-jet) is well examined considering six values of both slot locations $x_{s}$ and slot angle $\theta$ and four values of slot width $b$ were examined, as illustrated in Table 1. For each run, values of $y_{1}, y_{2}$, $L_{J}, Q_{S}$ and $Q_{T}$ were measured also, values of $Q_{S} / Q_{T}$, $y_{2} / y_{1}, L_{J} / y_{1}$ and $E_{L} / y_{1}$ were estimated. The obtained results revealed that, there is a significant decrease in values of $y_{2} / y_{1}$ and $L_{J} / y_{1}$ in comparison to those obtained for the free jump condition, whereas a slight increase is noticed in the values of $E_{L} / y_{1}$ and the best results of those values are recorded when the slot angle $\theta=45^{\circ}$, slot location $x_{s}=15 \mathrm{~cm}$ and slot width $b=0.30 \mathrm{~cm}$.

Tables 4 and 5 summarize the measured and calculated data for the perfect forced jump, respectively, for the proper value of the distance $x_{s}$, the angle $\theta$ or the width $b$ of slot.

\begin{tabular}{|c|c|c|c|c|c|c|c|c|}
\hline $\mathrm{cm}$ & $\frac{Q_{W}}{\mathrm{~cm}^{3} / \mathrm{s}}$ & $\frac{Q_{S}}{\mathrm{~cm}^{3} / \mathrm{s}}$ & $\frac{Q_{T}}{\mathrm{~cm}^{3} / \mathrm{s}}$ & $\mathrm{cm}$ & $\frac{y_{2}}{\mathrm{~cm}}$ & $\frac{L_{J}}{\mathrm{~cm}}$ & $F_{1}$ & $Q_{S} / Q_{2}$ \\
\hline 57 & 500 & 391 & & & & & & \\
\hline & & & & & & & & \\
\hline & 1500 & 319 & & & & 28.0 & 1 & \\
\hline & 2000 & 378 & & & & & & \\
\hline 49.85 & 2500 & 412 & 2912 & 1.13 & 11.75 & 47.0 & 8.74 & 0.14 \\
\hline
\end{tabular}

Table 4. Measured data for the perfect forced jump, where; $\theta=$ $45^{0}, x_{s}=15 \mathrm{~cm}$ and $b=0.30 \mathrm{~cm}$.

\begin{tabular}{|c|c|c|c|c|c|c|}
\hline$y_{2} / y_{1}$ & $L_{J} / y_{1}$ & $E_{L}$ & $E_{L} / y_{l}$ & $\Delta\left(y_{2} / y_{1}\right) \%$ & $\Delta\left(L_{J} / y_{l}\right) \%$ & $\Delta\left(E_{L} / y_{l}\right) \%$ \\
\hline & & $\mathrm{cm}$ & & & & \\
\hline 15.34 & 44.83 & 21.72 & 74.89 & 11.02 & 43.47 & 1.35 \\
\hline 11.6 & 40.0 & 29.52 & 59.04 & 22.7 & 42.86 & 4.9 \\
\hline 10.75 & 38.36 & 29.67 & 40.63 & 18.25 & 37.77 & 5.32 \\
\hline 10.74 & 41.49 & 30.3 & 32.23 & 10.28 & 26.41 & 3.2 \\
\hline 10.40 & 41.59 & 32.03 & 28.34 & 7.8 & 22.95 & 2.56 \\
\hline
\end{tabular}

Table 5. Calculated data for the perfect forced jump, where; $\theta=$ $45^{0}, x_{s}=15 \mathrm{~cm}$ and $b=0.30 \mathrm{~cm}$.

where; $\Delta\left(y_{2} / y_{1}\right) \%=$ Percentage decrease in values of $\left(y_{2} / y_{1}\right)$ due to effect of cross-jet, in which:

$$
\Delta\left(y_{1} / y_{2}\right) \%=\frac{\left(y_{1} / y_{2}\right)_{0}-\left(y_{1} / y_{2}\right)}{\left(y_{1} / y_{2}\right)_{0}} \times 100
$$

similarly, for the relative length of jump and for the relative energy dissipation along the jump. 


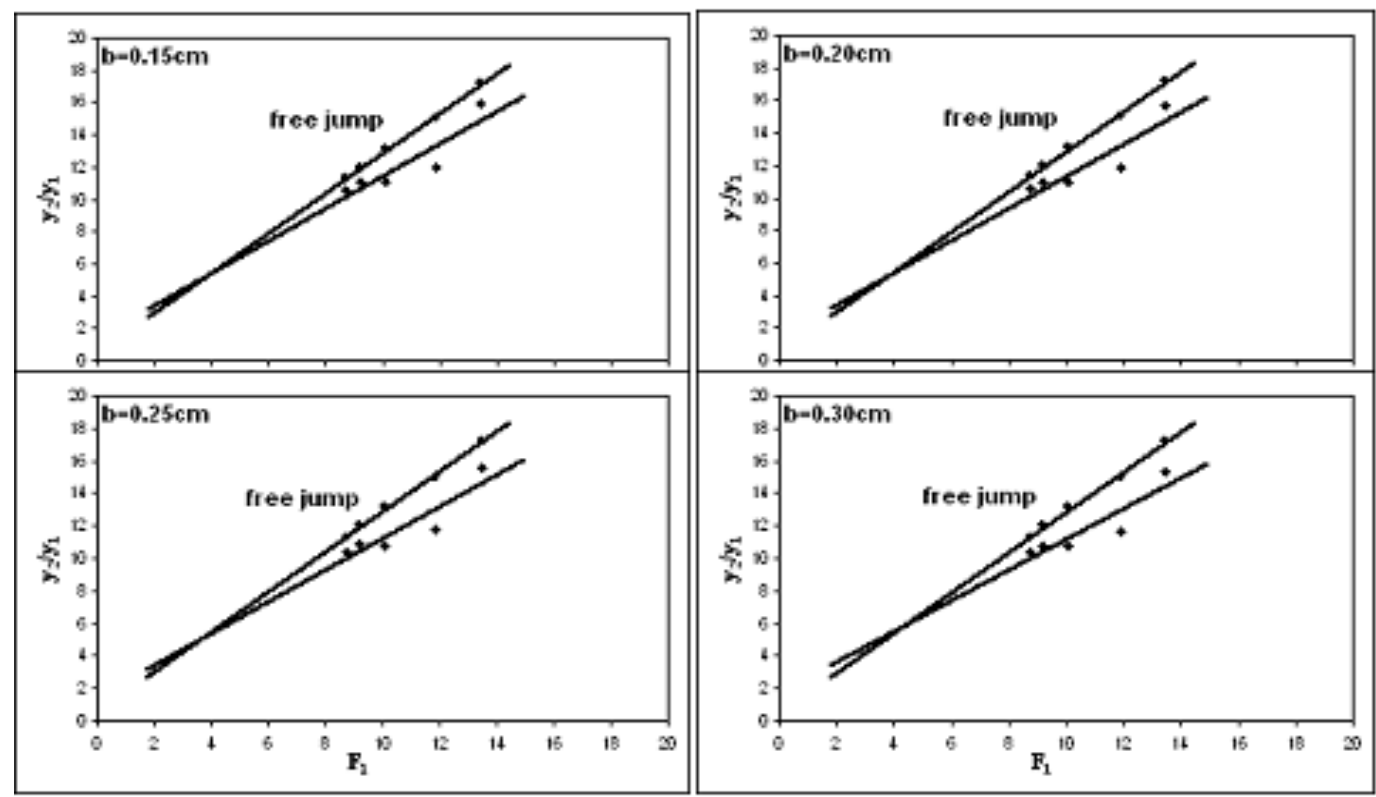

Figure 6. Relation between the conjugate depth ratio $\left(y_{2} / y_{1}\right)$ and Froude number $F_{1}$ for different values of slot width $b$, when $x_{s}=15 \mathrm{~cm}$ and $\theta=45^{\circ}$.

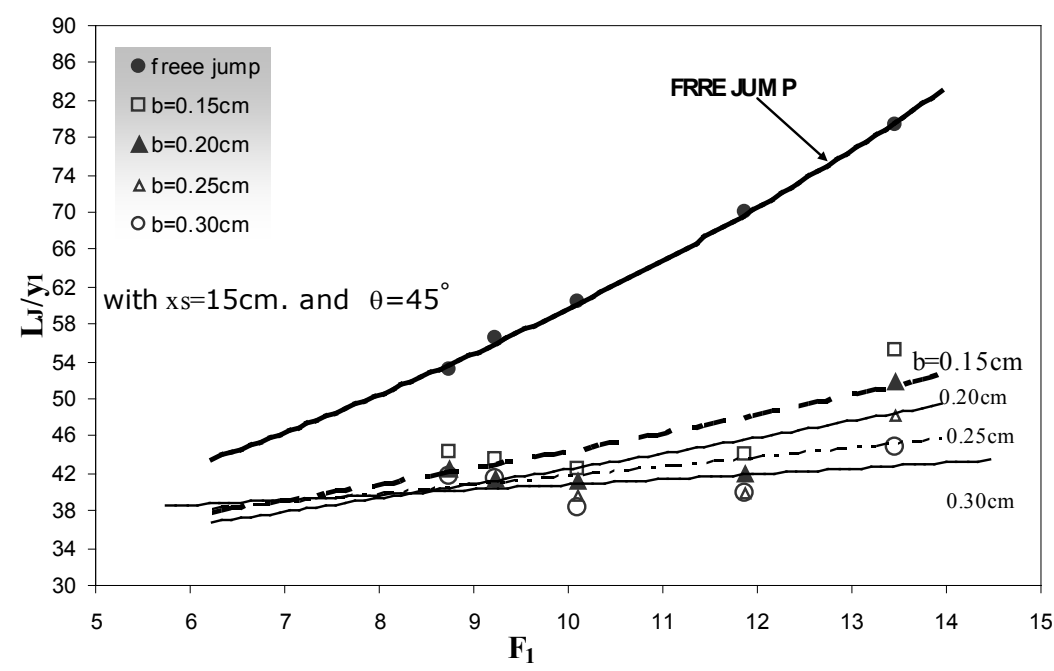

Figure 7. Relation between the relative jump length $\left(L_{J} / y_{1}\right)$ and Froude number $F_{1}$ for different values of slot width $b$, when $x_{s}=15$ $\mathrm{cm}$ and $\theta=45^{\circ}$.

Figures 6 and 7, illustrate the relationship between the main parameters involved in the current problem; the distance of slot location $x_{s}$, the angle of slot $\theta$, the width of slot $b$, and Froude number of the incoming flow $F_{1}$. Different values of $x_{s}, \theta, b$ and $F_{1}$ were experimentally investigated as indicated in Table 1, where the input data is the tested values of $x_{s}$, $\theta, b$ and $F_{1}$ while the output data is the conjugate depths of the formed hydraulic jump $y_{1}$ and $y_{2}$, the length of the jump $L_{J}$ and the loss of energy along the jump $E_{L}$. Note that these figures represent only the proper value of the distance $x_{s}$, the angle $\theta$ or the width $b$ of the slot that gives minimum values of both relative length of jump $L_{J} / y_{1}$ and conjugate depths ratio $y_{1} / y_{2}$ and maximum values of the relative energy dissipated through the jump $\left(E_{L} / y_{1}\right)$, as shown in tables 4 and 5 . In other words, it is the final step of testing the parameters $x_{s}, \theta$ and $b$.

The results reveal that, the maximum value of $\Delta\left(y_{2} / y_{1}\right) \%=22.70 \%$ when $F_{1}=11.88$. It is found also, that the difference between the maximum value of $\Delta\left(y_{2} / y_{1}\right) \%$ obtained when $b=0.15 \mathrm{~cm}$ and the maximum value found when $b=0.30 \mathrm{~cm}$ is only about $2.70 \%$ while the corresponding increase in slot width is $100 \%$. This indicates that the rate of decrease in values of $\left(y_{2} / y_{1}\right)$ is too small compared to the great increase in values of slot width, $b$. As for the relative length, it is clear from the table that the maximum value of $\left(L_{J} / y_{1}\right)$ is about $43.5 \%$. It is found also, that increasing the slot width $b$ by two times causes an increase in the maximum values of $\Delta\left(L_{J} / y_{1}\right) \%$ by $6 \%$. 
Analyzing the shape of the formed jump with respect to the slot width $b$, four experiments were carried out using different values of slot width $b$, where $b=0.15 \mathrm{~cm}, 0.20,0.25$ and $0.30 \mathrm{~cm}$. Other parameters were kept constant, thus; $x_{s}=15 \mathrm{~cm}, \theta=45^{0}$, and $F_{1}=10.10$.

Figure 8, shows the sequence of jump formation due to increasing the slot width $b$. It is clear from the figure that the length of jump decreases as slot width increases but with decreasing rate, compared to the case of a free jump. This is the reason why the increase in the maximum values of $\Delta\left(y_{2} / y_{1}\right) \%$ and $\Delta\left(L_{J} / y_{1}\right) \%$ is not matching the increase of slot width $b$.

It is noted from the experiments that, when the width of slot is greater than the considered range, in the present study, an overhead jump occurs and falls away with a length bigger than the length of the free jump, as shown in Figure 9. In this case, the flow issuing from the slot is strong as the jump is lifted to a high head and then falls down at a distance from the contracted section that is usually longer than the length of the free jump. In this case, the falling flow at the end of the jump produces high velocities near the channel bed, causing excessive dangerous eddies, and so it is not ideal.
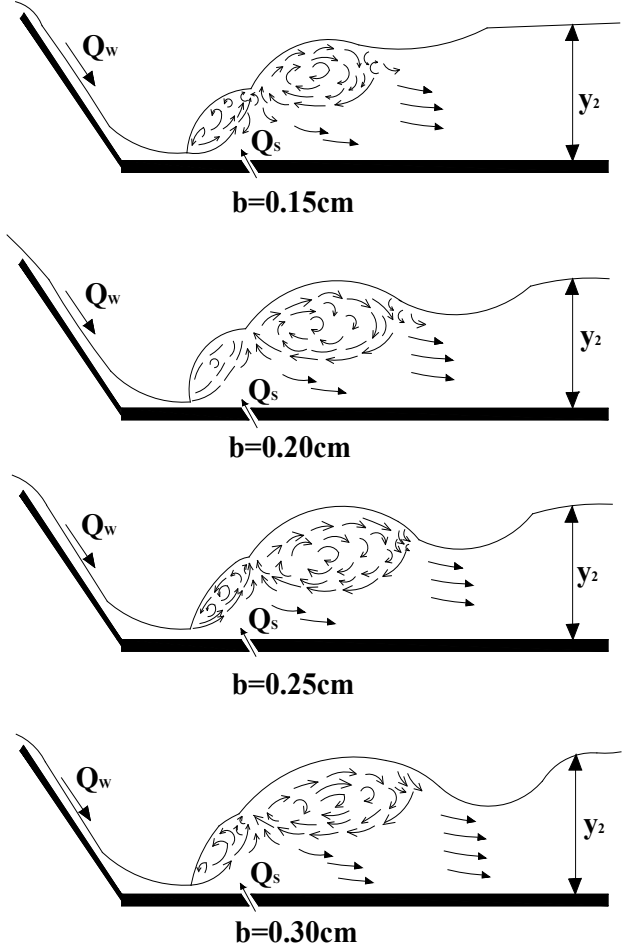

Figure 8. Effect of increasing slot width on the shape of the formed jump.

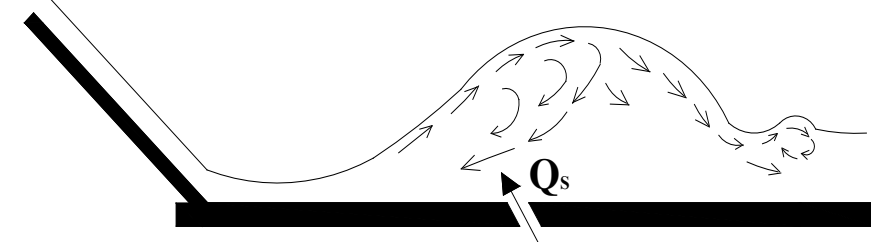

$$
\text { b }>0.30 \mathrm{~cm}
$$

Figure 9. The shape of the overhead jump resulting due to increasing slot width.

\subsection{Effect of the considered parameters on the discharge characteristics of the slot}

Experimental results indicated that the discharge of slot $Q_{S}$ is greatly affected by slot characteristics; position $x_{s}$, direction $\theta$ and width $b$ in addition to Froude number $F_{1}$.

The relative discharge $Q_{S} / Q_{T}$ generally increases as Froude number $F_{1}$ increases. It is seen that when the distance of slot location $x_{s}$ increases, the values of $Q_{S} / Q_{T}$ decreases, This result is logical since the head on the slot $h_{s}$ decreases as $x_{s}$ increases and in turn the slot discharge decreases, according to (Eq. 7) and (Fig. 3). The angle of slot $\theta=45^{\circ}$ gives the maximum value of $Q_{S} / Q_{T}$, while $\theta=90^{\circ}$ gives the lowest value. Increasing the slot width $b$ results in an increase in the value of the relative discharge $Q_{S} / Q_{T}$ but with decreasing rate. The percentage increase in values of $Q_{S} / Q_{T}$ is about $40 \%$ to $65 \%$ due to increasing the slot width two times, from 0.15 to 0.30 $\mathrm{cm}$, according to the considered range $F_{1}$.

\section{CONCLUSION}

A comprehensive analytical and experimental study had been conducted, in the present work, on the cross-jet flow when used to dissipate the energy of the flow falling over an ogee weir spillway since it's back face presents an inclined surface. The obtained results insure that the control of the hydraulic jump, formed downstream of an ogee weir spillway, is possible using the reversed cross-jet dissipator. The suggested cross-jet dissipator can be used to convert the repelled hydraulic jump not only to a perfect jump but also to a drowned jump and hence reduces the length of solid floor required, to a large extent. In addition, the tailwater depth could be reduced to about $77 \%$ of its original value at the same Froude number $F_{l}$ and the same initial depth $y_{l}$ of the falling flow, using the reversed cross-jet.

The results obtained, together with the developed formula 15 and 19, can be used to predict the conjugate depth ratio $\psi=y_{2} / y_{1}$ and the loss of energy for a hydraulic jump controlled by the reversed cross-jet. Locating the cross-jet flow within the length of the forced perfect jump, as close as possible to the contracted section, gives the minimum value of both the 
conjugate depth ratio and jump length, and the maximum value of the energy loss. A numerical example is applied and some relationships and derived equations were used, the obtained results revealed that, the cross-jet flow shortens the length of the solid floor, required for a repelled jump, by $79 \%$ while the reduction in the jump length itself amounted to $19 \%$.

According to the above conclusions, the following conditions should be recommended: (i) The reversed cross-jet dissipator is recommended to dissipate the energy of flow falling over inclined surfaces due to its high efficiency. (ii) The cross-jet flow is recommended to be located just behind the contraction section. (iii) The width of cross-jet flow should not exceed the value of the contracted depth.

\section{REFERENCES}

Abbasi, S. \& Kamanbedast, A. (2012). Investigation of Effect of Changes in Dimension and Hydraulic of Stepped Spillways for Maximization Energy Dissipation. World Applied Sciences Journal 18(2): 261-267.

Abourohim, M. A. (1991). Characteristics of Flow Over Ungated Ogee Weir Spillway. Alexandria Eng. Journal 30(3).

Amador, A. et al. (2009). Developing Flow Region and Pressure Fluctuations on Steeply Sloping Stepped Spillways. J. Hydraul. Eng. 135(2): 1092-1100.

Barani, G. A. et al. (2005). Investigation of Flow Energy Dissipation over Different Stepped Spillways. American Journal of Applied Sciences 2(6): 1101-1105.

Boes, R. \& Hager, W. (2003). Two-phase Flow Characteristics of Stepped Spillways. J. Hydraul. Eng. 129(9): 661-670.

Chafi, C. et al. (2010). Study of Flow and Energy Dissipation in Stepped Spillway. Jordan Journal of Civil Engineering 4 (1): $1-11$.

Chamani, M. R. \& Rajaratnam, N. (1999). Onset of Skimming Flow on Stepped Spillways. J. Hydraulic Engineering 125(9): 969-971

Chanson, C. (2004). The hydraulics of Open Channel Flow. Oxford: Elsevier Butterworth-Heinemann.

Chanson, H. (1994a). Comparison of Energy Dissipation Between Nappe and Skimming Flow Regimes on Stepped Chutes. J. Hydraulic Research, ASCE. 32(2): 213-218.

Hager, W. (2007). Scour in Hydraulic Engineering. Proceedings of the ICE - Water Management 160(3): 159-168.

Hager, W. H. \& Bremen, R. (1989). Classical Hydraulic Jump; Sequent Depths. J. Hydraul. Res. 27(5): 565-585.

Kao, T. Y. (1971). Hydraulic jump assisted by cross jet. Proc. ASCE, J. Hydraulic division 97(HY 12): 2037-2050.

Komora, Y. (1969). Spillway Design Using Jet Collision for Energy Dissipation. Power Technology and Engineering (formerly Hydrotechnical Construction). 3(4): 363-364.

Manoochehr, F. et al. (2011). Reduction of Stilling Basin Length with Tall End Sill. Journal of Hydrodynamics 23(4): 498-502.

Novak, P. \& Cabelka, J. (1981). Modes in Hydraulic Engineering: Physical Principles and Design Applications. London: Pitman.

Novak, P. et al. (2001 \& 2006). Hydraulic Structures. London: Spon Press.

Rajaratnam, N. (1976). Turbulent jets. Amsterdam, The Netherlands: Elsevier Science.

Simon, A., Korom, S. (1997). Hydraulics. New Jersey: Prentice-Hill, Inc.
Stephenson, D. (1991). Energy dissipation down stepped spillways, Water power \& Dam construction 42 (9): 27-30.

USBR hydraulic design of stilling basins and energy dissipators, Engineering Monograph No.25.

Verma, D.V.S. (2000). Stilling Basins for Pipe Outlets Using Wedge-Shaped Splitter Block. Journal of Irrigation and Drainage Engineering 126(3): 179-184.

Vischer, D. \& Hager, W. (1995). Energy dissipators. Balkema, Rotterdam: the Netherlands.

Vischer, D. \& Hager, W. (1998). Dam Hydraulics. Chichester: John Wiley \& Sons, Ltd.

Vollmer, E. \& Khader, M. H. (1971). Counter Current Energy Dissipator for Conduit Outlets. International Journal of Water \& Power 23(7): 260-263. 